\title{
Improvements in Off-Center Focusing in an X-ray Streak Camera
}

\author{
J. W. McDonald, F. Weber, J. P. Holder, P. M. Bell
}

This article was submitted to

The International Symposium on Optical Science and Technology, San Diego, CA August 3-8, 2003

Lawrence

Livermore

July 17, 2003

National

Laboratory

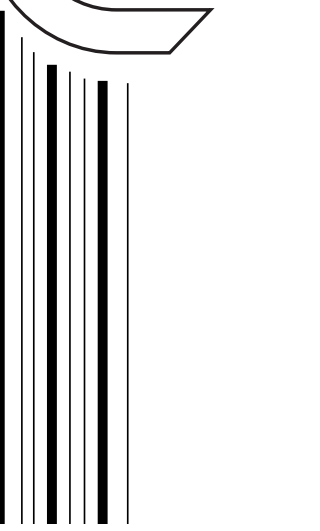




\section{DISCLAIMER}

This document was prepared as an account of work sponsored by an agency of the United States Government. Neither the United States Government nor the University of California nor any of their employees, makes any warranty, express or implied, or assumes any legal liability or responsibility for the accuracy, completeness, or usefulness of any information, apparatus, product, or process disclosed, or represents that its use would not infringe privately owned rights. Reference herein to any specific commercial product, process, or service by trade name, trademark, manufacturer, or otherwise, does not necessarily constitute or imply its endorsement, recommendation, or favoring by the United States Government or the University of California. The views and opinions of authors expressed herein do not necessarily state or reflect those of the United States Government or the University of California, and shall not be used for advertising or product endorsement purposes.

This is a preprint of a paper intended for publication in a journal or proceedings. Since changes may be made before publication, this preprint is made available with the understanding that it will not be cited or reproduced without the permission of the author.

This work was performed under the auspices of the United States Department of Energy by the University of California, Lawrence Livermore National Laboratory under contract No. W-7405-Eng-48.

This report has been reproduced directly from the best available copy.

Available electronically at http://www.doc.gov/bridge

Available for a processing fee to U.S. Department of Energy

And its contractors in paper from

U.S. Department of Energy

Office of Scientific and Technical Information

P.O. Box 62

Oak Ridge, TN 37831-0062

Telephone: (865) 576-8401

Facsimile: (865) 576-5728

E-mail: reports@adonis.osti.gov

Available for the sale to the public from

U.S. Department of Commerce

National Technical Information Service

5285 Port Royal Road

Springfield, VA 22161

Telephone: (800) 553-6847

Facsimile: (703) 605-6900

E-mail: orders@ntis.fedworld.gov

Online ordering: http://www.ntis.gov/ordering.htm

Or

Lawrence Livermore National Laboratory

Technical Information Department's Digital Library

http://www.llnl.gov/tid/Library.html 


\title{
Improvements in Off-Center Focusing in an X-ray Streak Camera
}

\author{
J.W. McDonald, F. Weber, R.L. Griffith, J.P. Holder, and P.M. Bell \\ Lawrence Livermore National Laboratory
}

\begin{abstract}
Due to the planar construction of present $\mathrm{x}$-ray streak tubes significant off-center defocusing is observed in both static and dynamic images taken with one-dimensional resolution slits. Based on the streak tube geometry curved photocathodes with radii of curvature ranging from 3.5 to 18 inches have been fabricated. We report initial off-center focusing performance data on the evaluation of these "improved" photocathodes in an Xray streak camera and an update on the theoretical simulations to predict the optimum cathode curvature.
\end{abstract}

Introduction

Many plasma physics studies require the recording of continuous time history of x-ray emission ${ }^{1}$. Instruments to record these $\mathrm{x}$-rays, $\mathrm{x}$-ray streak cameras, have been developed over the years and are available commercially. These cameras record x-rays by converting photons to electrons, then sweeping the electrons across an electron sensitive area detector as a function of time. A major component of a streak camera is the streak tube. In the streak tube photons are converted to electrons at the photocathode, these electrons are accelerated, focused, and deflected onto a detector or phosphor. In X-ray streak cameras, the planar geometry of the photocathode and acceleration grid combined with the need to focus the electrons on the planar CCD cause the electrons from the edges of the photocathode to arrive later in time and at a different focus than the electrons from the center. To minimize these aberrations an ideal camera would have both a curved photocathode-acceleration system and a curved detection system such as a curved CCD chip $^{2}$. At this time curved CCD chips are not yet readily available. Curved photocathodeacceleration systems have been manufactured and tested at Lawrence Livermore National Laboratory (LLNL) by the National Ignition Facility (NIF) Streak Camera Characterization Group. This paper includes a description of the experiments and simulations using SIMION ${ }^{3}$ and EGN2 ${ }^{4}$ that have been performed to choose the best radius of curvature for the cathode-acceleration grid assemblies. This paper provides an update on the state of an ongoing program to improve x-ray streak cameras ${ }^{5}$.

\section{Experiment}

The experimental setup consists of a Manson-type x-ray source operated with a $10 \mathrm{kV}$ and up to $1 \mathrm{~mA}$ electron beam current impinging onto a solid titanium target (Ti-K $\alpha$ at $4.51 \mathrm{eV}$ ), an X-ray shutter coupled to a Kentech ${ }^{6} \mathrm{Mk}$ II x-ray streak camera, and a Spectral Instruments ${ }^{7} 2 \mathrm{k}$ by $2 \mathrm{k}$ CCD camera. The chip is subjected to direct electron bombardment and features three phase architecture and a pixel size of $13.5 \mu \mathrm{m}$ by 13.5 $\mu \mathrm{m}$. For static tests the streak camera is operated in a DC mode (i.e., no streaking) with resolution grids of 20-50-75 $\mu \mathrm{m}$ slits on $1500 \mu \mathrm{m}$ center spacing. The resolution grid casts an x-ray shadow with known dimensions on the photocathode. The photons are converted to electrons accelerated and focused on to the CCD for imaging. The experimental setup showing the curved geometry is depicted schematically in Figure 1. In Figure $1 \mathrm{x}$-rays from the source illuminate the resolution mask or grid through an 
optional filter (not shown). The shadow created by the resolution mask results in a pattern of photons on the photocathode. These photons are converted to electrons which are accelerated and focused through the aperture and deflection plates on to the direct electron bombarded CCD. The radius of curvature (ROC) and the material of the photocathode-acceleration systems tested are summarized in Table 1.

Table 1 Photocathode-acceleration systems tested.

\begin{tabular}{|rl|l|}
\hline $3.5 ”$ & ROC & $\mathrm{Au} \_\mathrm{Be}$ \\
\hline $5 "$ & ROC & $\mathrm{Au} \_$Lexan \\
\hline $7 ”$ & ROC & $\mathrm{Au} \_\mathrm{Be}$ \\
\hline $10 ”$ & ROC & $\mathrm{Au} \_$Lexan \\
\hline $18 ”$ & ROC & $\mathrm{Au} \_$Lexan \\
\hline \multicolumn{2}{|c|}{ Flat } & $\mathrm{Au}$ \\
\hline
\end{tabular}

The mounting plates for the photocathodes and acceleration grids were manufactured such that the rear mounted photocathode and the front mounted acceleration grid had the same ROC and uniform separation. The 3.5 and 7 inch photocathodes and acceleration grids were manufactured at LLNL while the 5, 10, and 18 were manufactured by Luxel Corporation ${ }^{8}$. The Flat photocathode acceleration grids were made by both LLNL and Luxel. The gold on the multi-component photocathodes was vapor deposited and is expected to be uniform in thickness across the width producing uniform electron emission. The gold on the flat photocathode is manufactured with well characterized foil and is also expected to produce uniform electron emission. The camera was refocused (electronically) for each radius and resolution grid. The image of the center slit was adjusted for best focus for each case.

Data images were collected on a PC connected to a Spectral Instruments SI800 camera with a $2 \mathrm{k}$ by $2 \mathrm{k}$ back thinned 13.5 by $13.5 \mu \mathrm{m}$ CCD chip. These images were background subtracted and the fwhm of the intensity variations projected onto the CCD from the resolution mask were measured and tabulated. The results of these measurements are shown in Figure 2 for 3.5, 5, 7, 10, 18 and flat photocathode-acceleration grids. 
CCD Direct

Electron

Bombardment
Aperture

Focusing
Manson

Photo

Cathode
X-Ray

Point Source
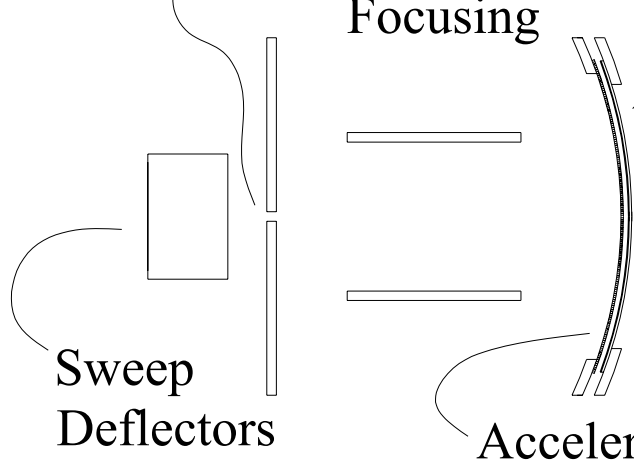

\section{Resolution \\ Mask}

\section{Acceleration}

\section{Grid}

Figure 1 Schematic diagram of Streak Camera. Photons from the Manson x-ray source, pass through an optional filter (not shown) and resolution grid (mask), forming a pattern on the photocathode where they are converted to electrons accelerated and focused onto the CCD camera.

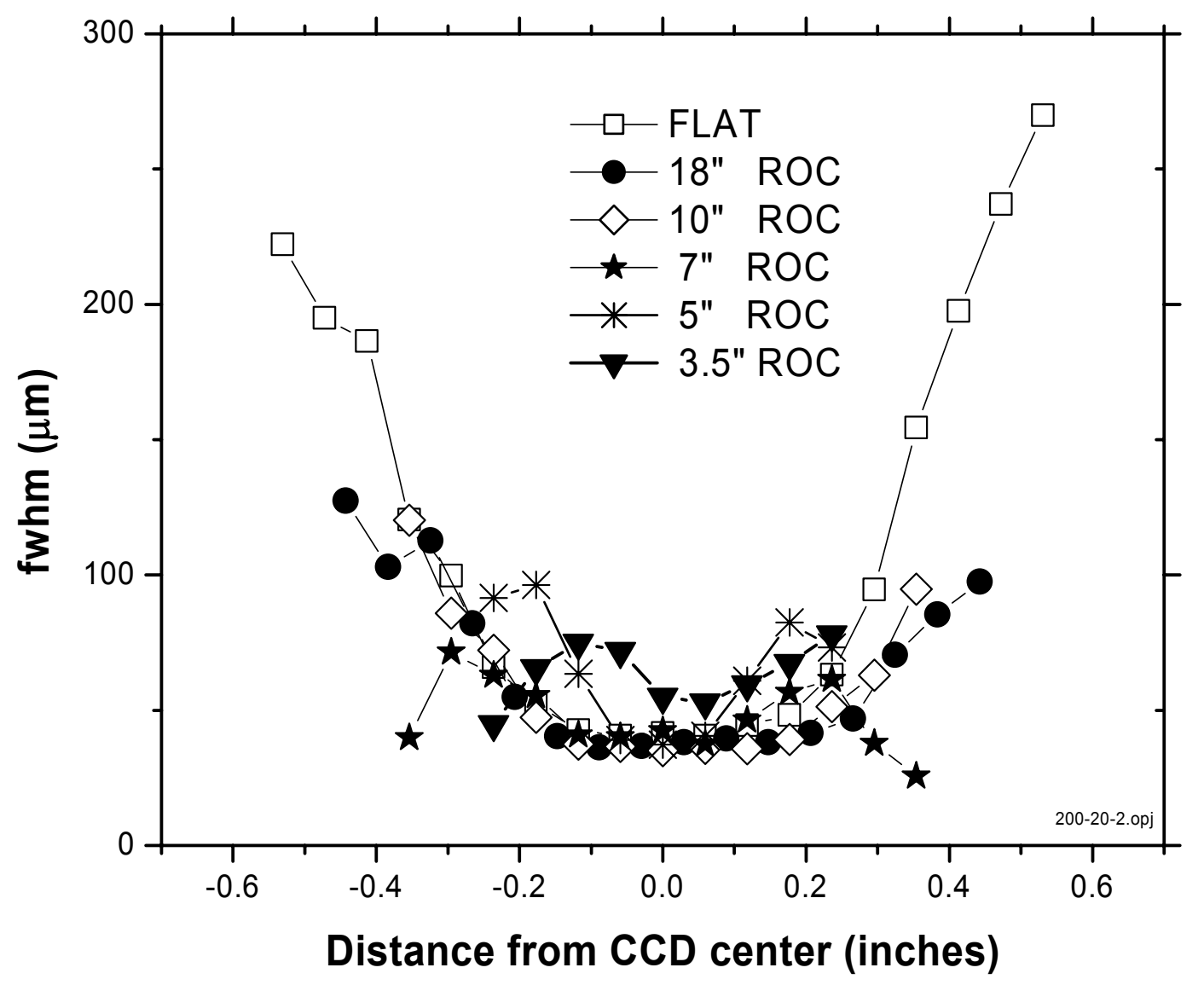

Figure 2 fwhm for $200 \mu \mathrm{A}, 20 \mu \mathrm{m}, 2$ s exposure all photocathode radii of curvature. Note the 18, 10 and 7 inch ROC focus a larger area of the photocathode onto the CCD. 


\section{$\underline{\text { Simulations }}$}

The x-ray streak camera system has been simulated using two software packages, SIMION version 7.0 and Electron Optics Program EGN2C: 3.365 the Herrmansfeldt electron gun simulation code. The SIMION simulations confirmed the experimental results but were inconclusive as to which ROC is optimum due to the granularity of the electrodes. The granularity of the SIMION electrode simulation is on the same order of magnitude as the resolution being simulated.

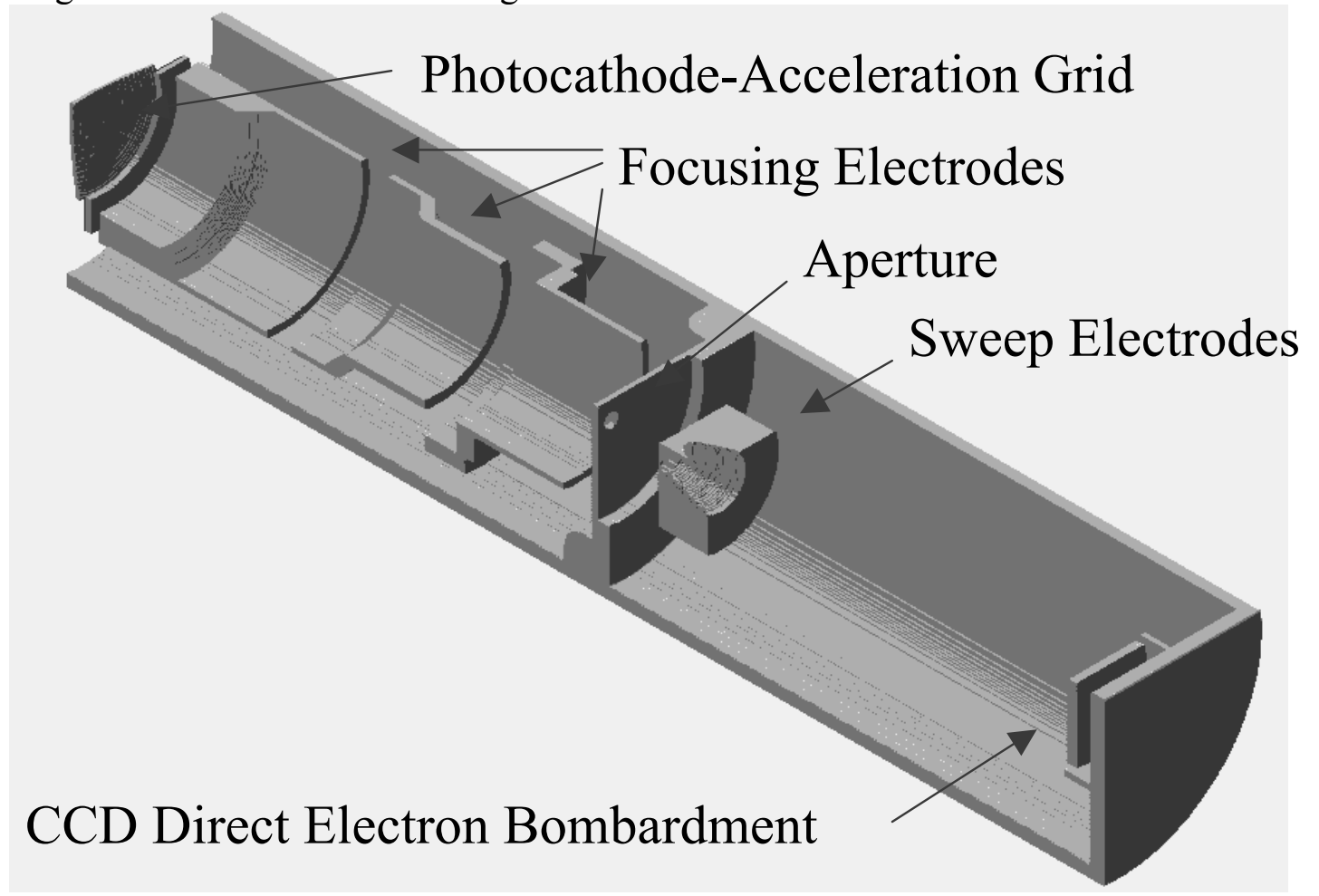

Figure 3 SIMION cutaway layout of streak tube geometry. Electrons from the photocathode (left) are accelerated and focused through the aperture and sweep electrodes onto the CCD (right)

A typical simulation employing the SIMION program requires a geometry file and an ion file. The geometry file defines the electrode potentials, locations and shapes that are used to produce the potential field that the charged particles are flown through. The ion file describes the charged particles (electrons in this case) and their properties (i.e., starting locations, energies, and directions). The geometry of the x-ray streak camera used in the SIMION simulation is shown in figure 3. This figure shows the major components of the $\mathrm{x}$-ray streak camera system. Starting at the top left with the photocathode-acceleration grid, focusing elements, aperture, sweep electrodes and direct electron bombardment CCD chip. Figure 4 shows a close up view of the SIMION simulation of the photocathode-acceleration grid area of the x-ray streak tube. The bottom edge of this figure represents the center line of a cylinder that the elements should be rotated around to form the 3 dimensional representation of the $\mathrm{x}$-ray streak camera system. Figure 5 shows an enlarged view of the photocathode acceleration region emphasizing the granularity of the SIMION simulations. The simulated distance between the photocathode (left) and the acceleration grid (thin line) is two millimeters the step size on 
the photocathode and acceleration grid is on the order of $150 \mu \mathrm{m}$. This granularity of SIMION led us to change to the Herrmansfeldt Electron Optics Program.

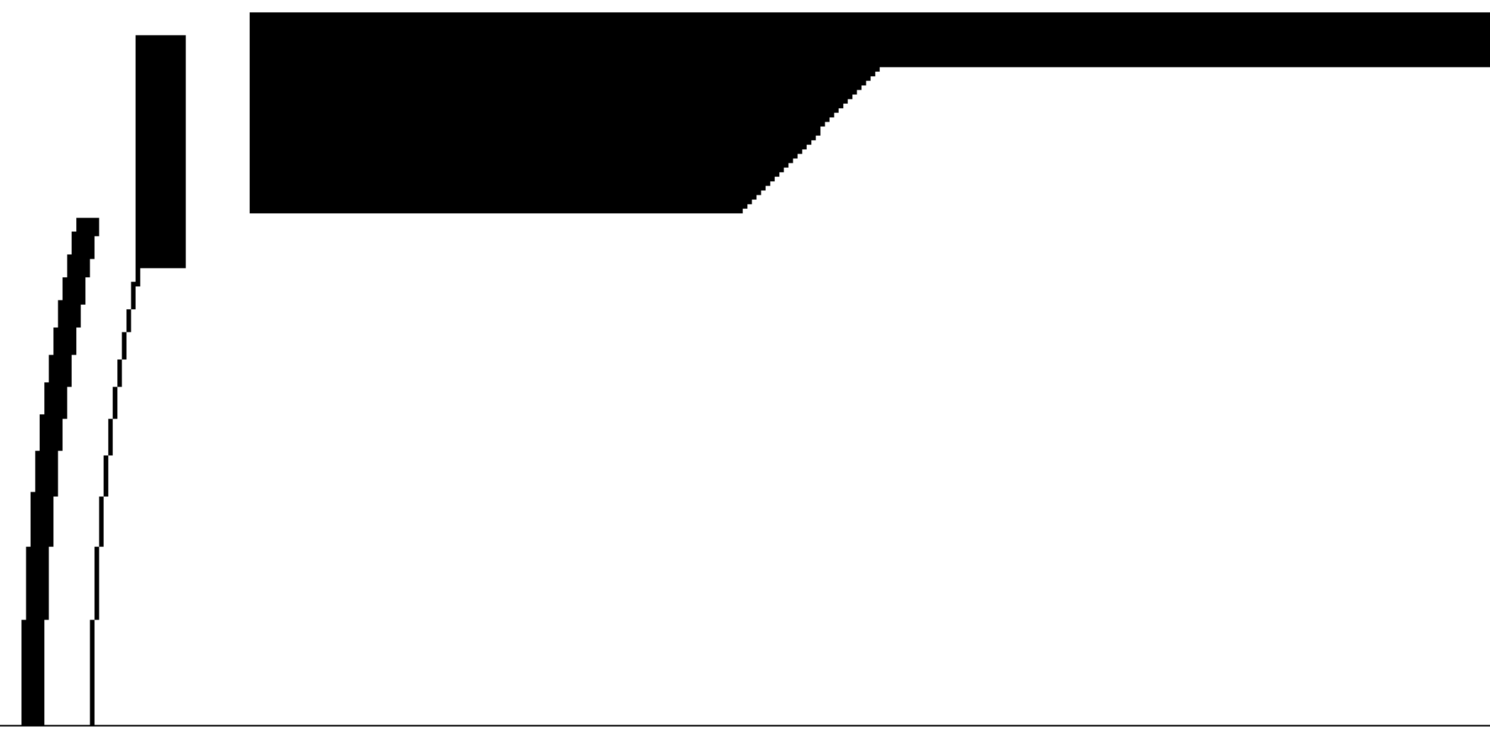

Figure 4 Two dimensional view of x-ray streak camera simulation in SIMION. The electrodes shown from left to right are photocathode, acceleration grid and first focusing element. The separation between the photocathode and the acceleration grid is $2 \mathrm{~mm}$. The electrode granularity is on the order of $150 \mu \mathrm{m}$.

A typical simulation employing the Electron Optics Program requires a geometry file that is preprocessed into an input file which is then used by the program to calculate the potential map of the simulation space. The electron optics program geometry is depicted in Figure 6 for the case of a 10 inch ROC photocathode at $-15.0 \mathrm{kV}$, acceleration grid at $14.8 \mathrm{kV}$, focusing electrodes at $-13.3,0.0$ and $-11.6 \mathrm{kV}$. These potentials agree reasonable well with the experimental values. As in the SIMION simulation the bottom of the image is the centerline of a cylinder of rotation that forms the electrode geometry. Simulations were performed for 3.5, 5.0, 7.0, 10.0, 14.0 and 18.0 inch ROCs as well as for flat photocathode acceleration pairs. 


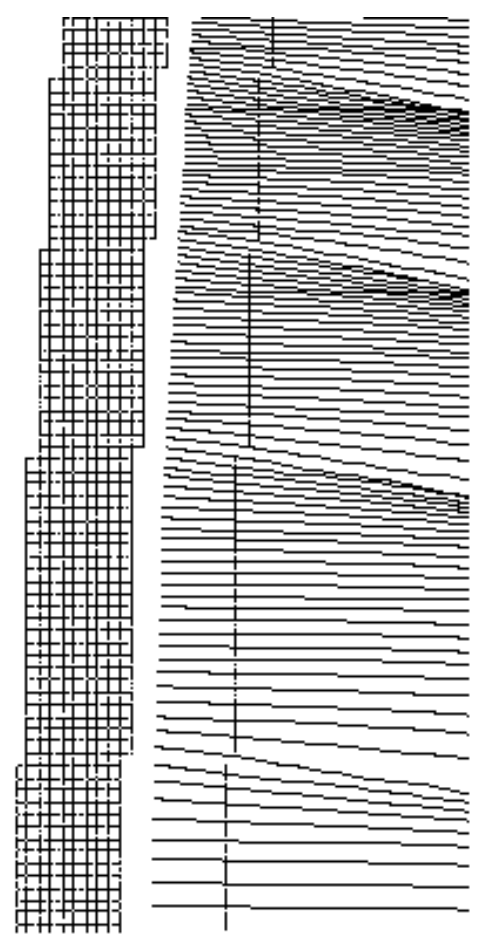

Figure 5 Enlarged view of SIMION simulation showing granularity of photocathode-acceleration grid. The photocathode is on the left and the thin vertical line to the right is the acceleration grid. The separation between the photocathode and the acceleration grid is $2 \mathbf{~ m m}$ and the step size is $150 \mu \mathrm{m}$.

\section{Discussion}

Extensive mages were collected for several x-ray intensities and each resolution grid on the DC Manson x-ray source. Data analysis was accomplished with IDL scripts on a PC. The images were background corrected by subtraction of an image taken without x-rays. Line outs were taken for each of the images. The data were collected and analyzed to find the relative intensity and full width at half maximum (fwhm) across the width of the output image for each ROC. The image of the resolution mask produces regularly spaced peaks on a lineout of the background subtracted CCD image. The width of these peaks is used to find the width of the image projected on the photocathode. The fwhm of the projected resolution mask slits for $200 \mu \mathrm{A}$ electron beam current and $20 \mu \mathrm{m}$ openings in the resolution grid at $2 \mathrm{~s}$ exposure are plotted in Figure 2. Analysis of this plot leads to the conclusion that both the 18, 10 and the 7 inch ROC indicate an improvement of approximately $20 \%$ over the flat photocathode. It is clear that smaller ROC photocathodes have a narrow field of view. At first observation the 7 inch ROC looks like it has the widest usable area of photocathode. However the intensity variations shown in Figure 6 clearly show that with the existing photocathode-acceleration grids the 18 and 10 inch ROC give the best results.

These experimental results have been compared with SIMION and Electron Optics program simulations and found to agree with the simulations. 


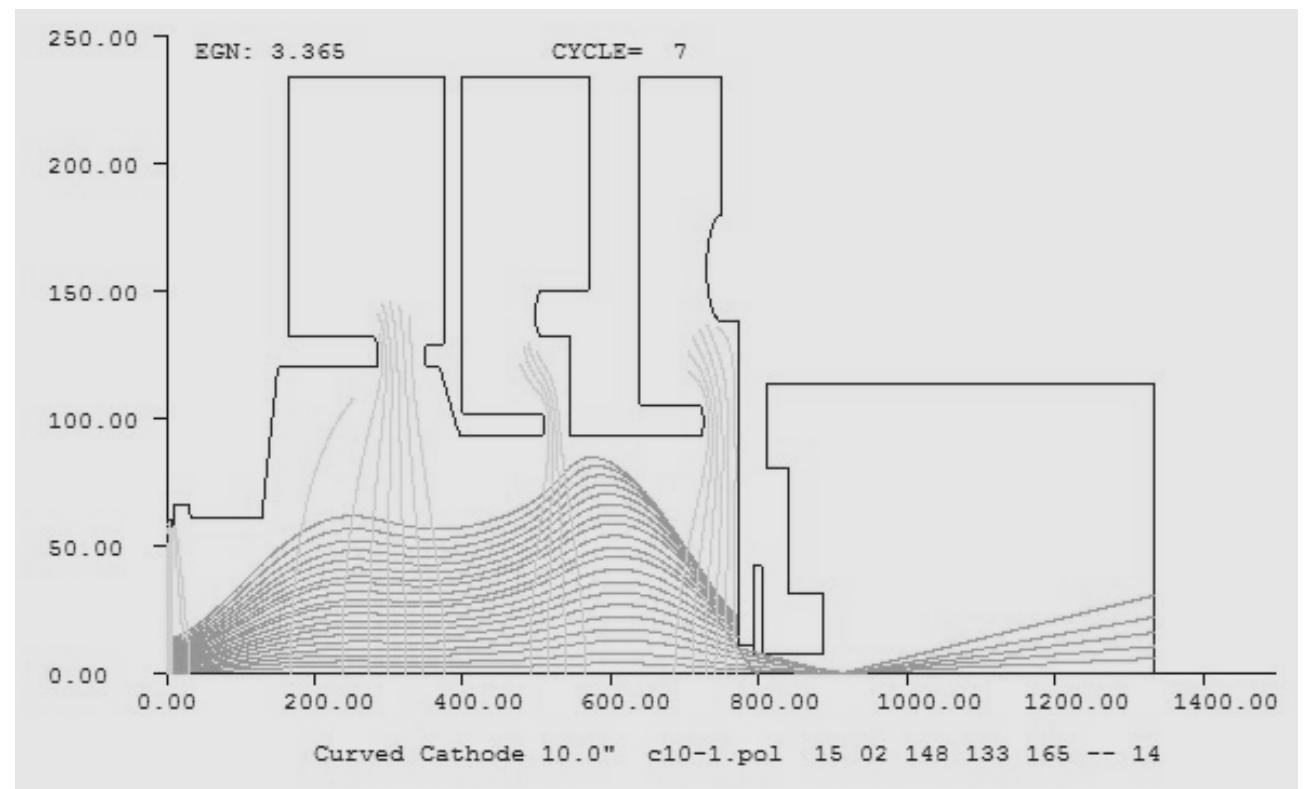

Figure 6 Electron Optics program output image for the 10 inch ROC photocathode with the potentials listed in the text.

FLAT

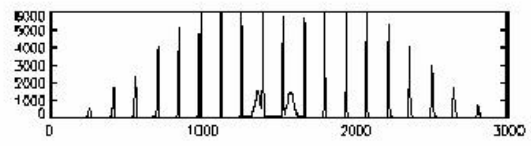

$18^{\prime \prime}$

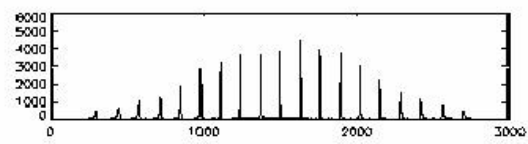

$10^{\prime \prime}$

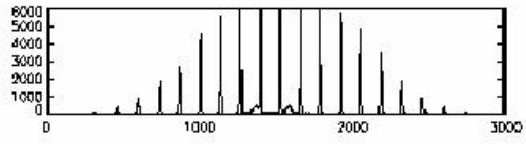

$7^{\prime \prime}$

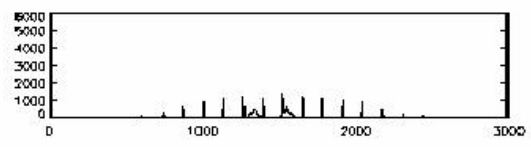

$5^{\prime \prime}$

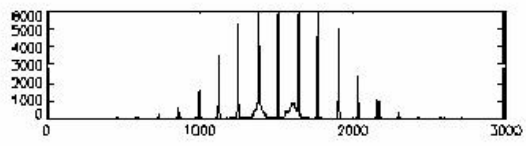

$3.5^{\prime \prime}$

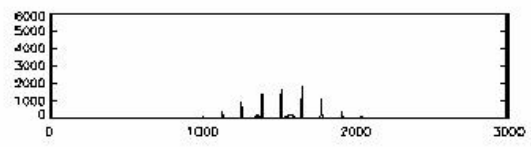

Figure 7 Intensity variations for the various photocathode-acceleration configurations tested. Note each spectra is plotted on the same scale. The 7 and 3.5 ROC photocathodes are vapor deposited on Be substraights and show the lowest intensities. 
It is clear that the flexibility of the camera system in terms of electrical potential focusing make the selection of an optimum ROC difficult. The simulations are also susceptible to the focusing properties of the camera system. Simulations of ROCs show and improvement over the flat photochatode-acceleration system for the 10, 14 and 18 inch ROC but little difference between these three ROCs. This is in agreement with the experimental data.

Future improvements to the camera system should include higher transmission acceleration grid material, insulating coatings on the acceleration grid to reduce spontaneous electron emission, reduction in the photocathode acceleration grid separation (would be allowed by the insulation) and a curved CCD.

This work was performed under the auspices of the U.S. Department of Energy by University of California Lawrence Livermore National Laboratory under Contract No. W-7405-ENG-48.

\footnotetext{
${ }^{1}$ David Attwood, "SOFT X-RAYS AND EXTREME ULTRAVIOLET RADIATION", Cambridge University Press, New York, New York, ISBN 0521652146 (1999) and John D. Lindl, "Inertial Confinement Fusion", AIP PRESS - Springer-Verlag, New York, New York, ISBN 1-56396-662-X (1998)

${ }^{2}$ Illes P. Csorba, 'IMAGE TUBES”, Howard W. Sams \& C0., Inc, Indianapolis, IN

${ }^{3}$ SIMION 3D 7.0, David A. Dahl, MS2208,Idaho National Engineering and Environmental Laboratory, P.O. Box 1625, Idaho Falls, ID 83415

${ }^{4}$ Electron Optics Program: EGN2C: 3.365, W. B. Herrmannsfeldt, P.O. Box 20450, Stanford, CA 94309

${ }^{5}$ J. W. McDonald, F. Weber, K. W. Piston, E. O. Vergel DeDios, J. P. Holder and P. M. Bell, RSI, 74, 3 (2003) 2245.

${ }^{6}$ Kentech Instruments Ltd., Unit 9, Hall Farm Workshops, South Moreton, Didcot, Oxfordshire, OX11 9AG, U.K. http://www.kentech.co.uk/

${ }^{7}$ Spectral Instruments 420 North Bonita Avenue Tucson, Arizona 85745 http://www.specinst.com/

${ }^{8}$ LUXEL CORPORATION P.O. Box 1879 (Mail) 515 Tucker Ave (Parcels) Friday Harbor, WA 98250

USA http://www.luxel.com
} 